\title{
WEBQUEST AS TECHNOLOGY OF DIFFERENTIATED ESP INSTRUCTION AT UNIVERSITY LEVEL
}

\author{
Oksana Synekop \\ National Technical University of Ukraine "Igor Sikorsky Kyiv Polytechnic Institute”, Ukraine \\ E-mail: oksana.synekop@gmail.com
}

\begin{abstract}
The current study aims to find out teachers' attitudes to the WebQuest learning and analyze the specifics of WebQuests and possibilities of their use in differentiated ESP instruction of information technology (IT) students. A qualitative type of research was used. The participants of the study were 31 ESP teachers $(28$ females and 3 males) of the Department of English for Engineering of National Technical University of Ukraine "Igor Sikorsky Kyiv Polytechnic Institute". The ESP teachers participated in the study voluntarily in 2019-2020. An anonymous questionnaire was used to collect the data. The questioning of the ESP teachers has shown that most of them appreciate the idea of using the WebQuest learning. The analysis of the WebQuest specifics allowed suggesting a classification of WebQuests based on ten criteria. The structure of a WebQuest is described with a focus on IT students' language learning styles and foreign language proficiency levels. Approaches to the WebQuest learning used by ESP teachers in the differentiated instruction were analyzed. It was concluded that the use of different types of WebQuests with a focus on learners' differentiation helps to diversify ESP learning at technical university and facilitates the development of professional communicative skills.
\end{abstract}

Key words: differentiated instruction, WebQuest, IT students, English for Specific Purposes

\section{INTRODUCTION}

With rapidly developing information technologies (IT) throughout the world, technical universities are searching for new and effective ways of training highly qualified and competitive specialists with substantial professional knowledge and skills, ready to work at modern labour markets. To meet the contemporary professional standards and requirements, IT students have to be able to communicate in foreign languages at a level sufficient for addressing communication issues in the IT sector. In Ukrainian realities, new global demands dictate changes in English for Specific Purposes (ESP) learning and teaching.

An effective way to promote positive changes in the ESP teaching is to take into account the learners' differentiation (in English language proficiency levels and language learning styles) as well as to use appropriate digital tools in the learning process. With a wide range of current Internet resources for the differentiated ESP instruction, WebQuest technology deserves particular attention due to these features:

Submitted February $28^{\text {th }}, 2020$, accepted for publication April $3^{\text {rd }}, 2020$ 
- it gives an opportunity to meet the needs of IT students with different learning styles and foreign language proficiency levels;

- it allows students to practise foreign communicative skills (listening, speaking, reading, and writing) in simulated professionally oriented situations;

- it fosters the increase in the range of professional knowledge;

- it helps organize classroom and extracurricular activities in a flexible way.

\subsection{WebQuest CONCEPT}

As a multidimensional concept, a WebQuest is interpreted in different ways. For example, Abbit and Ophus (2008) define it as an instructional strategy, Halat (2010) - as a teaching tool and technique for internet-based learning. It is also viewed as "a teachercreated lesson plan in the form of a simple World Wide Web page with active, preselected Internet links and a specific purpose for students" (Kelly 2000, p. 4). The definitions of Dodge (1995) and Brooks-Young (2006) are focused on the WebQuest as an "activity". According to Dodge (1995), it is "an inquiry oriented activity in which some or all of the information that learners interact with comes from resources on the Internet" (Dodge 1995, p. 10). Similarly, Brooks-Young (2006) defines the WebQuest as "an activity based on the inquiry instructional approach where most or all of the information used by students is Internet-based" (p. 61). This gives ground to believe that a WebQuest is not only a web-based learning technology, but also a process and a strategy used by the teacher for guiding students in their problem solving activity.

\subsection{Literature review}

A whole number of recent publications are devoted to WebQuest and possibilities of its use in the learning process. They highlight the appropriateness of this technology for various categories of learners and a wide range of curriculum disciplines. At secondary school level AL-Khataybeh and AL-Awasa $(2016,112)$ investigated the effect of using a WebQuest on improving seventh grade female learners' writing skills. MacGregor and Lou (2004) researched its possibilities for providing instructional scaffolding to students. Their findings particularly indicated that "the concept map template was effective in guiding students' synthesizing and organizing the information they gathered for their target purpose and audience" (MacGregor, \& Lou 2004, p. 172). The results obtained by Renau and Pesudo $(2016,26)$ showed that the use of WebQuests motivated students to study English, helped to improve their digital and cultural competences. At university level, a WebQuest became an instrument for developing language receptive and productive skills. For example, Tuan (2011) examined the possibilities of a WebQuest for enhancing the intensive and extensive reading skills when using the constructivist approach, inquiry-based learning approach, project-based approach, and content-based language learning (2011, 666-667). He also found that the students had positive attitude towards the WebQuest-based teaching of reading. Berezova, Mudra and Yakushko (2018) used a WebQuest to improve writing and reading skills. Diachkova (2015) found WebQuests effective for the development of speaking skills of future lawyers at university. Pérez (2016) explored WebQuests in the context of blended and cooperative learning. The analysis of these works shows that different aspects of WebQuest use in foreign language teaching have been studied quite thoroughly. However, the functionality of this tool in differentiated ESP instruction may need further research. 


\section{The Aim OF THE CURRENT STUDY}

Thus, the aim of this study is:

1) to find out ESP teachers' attitudes to WebQuest learning at university;

2) to analyze the specifics of WebQuests and possibilities of their use in differentiated ESP instruction.

\section{METHODS}

\subsection{Research design}

The current study used the qualitative research method focused on collecting information about teachers' attitude to the WebQuest learning, analyzing the teachers' experience and gathered data for defining the specifics of WebQuests and possibilities to use them in the differentiated ESP instruction.

\subsection{Research participants}

The participants of the study were 31 teachers (28 females and 3 males) of the Department of English for Engineering of National Technical University of Ukraine "Igor Sikorsky Kyiv Polytechnic Institute". The teachers who volunteered in the current study taught ESP to technical students. This research took place in 2019-2020.

\subsection{Research instruments and procedures}

Initially, the observation of some teachers was conducted during the WebQuest learning. Then, an anonymous questionnaire was used. This questionnaire contained 10 questions with variants of answers which could be chosen by the respondents. The time needed to complete the questionnaire was about 7-10 minutes. The questions were as follows:

1. Would you like to use the WebQuest learning instead of traditional ESP classes?
a) Yes, fully
b) Yes, partially
c) $\mathrm{No}$

2. I use the WebQuest learning because:
a) it helps to develop students' foreign language communication skills
b) it facilitates the acquisition of professional knowledge by students
c) it promotes students' critical thinking, collaborative, self-directed learning skills
d) all the above mentioned

3. In the WebQuest learning I would like to take/have taken into consideration the learners' differentiation (in language learning styles, English proficiency levels):
a) In all tasks
b) In several tasks
c) In one task
d) In no tasks 
4. In my opinion, learners' autonomy should be provided in the WebQuest learning.
a) full (the students perform the tasks without the teacher's help)
b) partial (the students perform the tasks with the teacher's help)
c) full and partial

5. Where can a WebQuest be used?
a) in classroom
b) out of classroom
c) in and out of classroom

6. What types of assessment are appropriate for the WebQuest learning of technical students? More than one answer can be chosen.
a) formative assessment
b) summative assessment
c) both formative and summative assessment

7. The most acceptable duration of a WebQuest for technical students is
a) one-two weeks (short-term WebQuest)
b) one-two months (medium-term WebQuest)
c) one semester (long-term WebQuest)
d) all of the above

8. According to the criterion of the "number of performers", it is most appropriate to organize WebQuests as
a) individual
b) pair
c) small group
d) whole academic group

9. It is better to focus on WebQuests that involve

a) discrete skills (listening, speaking, reading or writing)

b) integrated skills (for example, reading and writing, speaking and writing etc.)

10. It is better to use in the WebQuest learning.

a) separated tasks (creative product task, persuasion task, analytical task, self-knowledge task etc.)

b) combined tasks

\subsection{Data Analysis}

The process of data analysis involved three stages. First of all, the WebQuest learning was used by the ESP teachers in the learning process for defining its specifics. Then, a questionnaire was used to find out the teachers' attitudes to the WebQuest learning and the data obtained were processed. Finally, the results were interpreted and the conclusions were made. 


\section{RESULTS}

Survey of 31 ESP teachers has shown that most of them $(87.09 \%)$ appreciate the idea of using the WebQuest learning and would like to replace traditional learning by the WebQuest learning partially, 9.68\% of teachers would like to substitute traditional learning by the WebQuest learning completely. And only a small percentage $(3.23 \%)$ of teachers does not consider it necessary to use this technology.

Most teachers (48.38\%) think that there are several reasons to use WebQuests in ESP learning. Among them are possibilities of WebQuests for the development of foreign language communication skills; acquisition of professional knowledge; promotion of critical thinking, development of collaborative, self-directed learning skills. Almost half of the teachers $(41.94 \%)$ believe that such skills as critical thinking, collaboration, and self-direction, are the basis for lifelong learning.

In all teachers' $(100 \%)$ opinion, learners' differentiation (in language learning styles, English proficiency levels) must be considered. Most of them $(83.87 \%)$ think that only certain tasks should be differentiated. Some teachers $(5 \%)$ believe that differentiation of learners should be considered in all tasks, since it allows meeting the needs and interests of students most fully. However, differentiation in learning requires a lot of teachers' efforts to create tasks for different students.

Teachers' viewpoints on learners' autonomy are quite diverse. During the WebQuest learning some teachers (16.13\%) preferred giving IT students the full autonomy, which is proper for those of them who have a high level of English language proficiency (B2) and can solve problems independently without teacher's help. Almost half of the teachers $(48.38 \%)$ prefer giving students partial autonomy, since the majority of them can fulfil tasks only with the help of the teacher. More than one third $(35.48 \%)$ of the teachers chose using both types of autonomy (full and partial), because they believe that varying the levels of autonomy is important in differentiated ESP instruction.

Since IT students have only one class (90 minutes long) per week, WebQuests can be used both in and out of classroom. Very few teachers prefer using them only in classroom or only out of classroom (3.23\% and $6.45 \%$, respectively). The majority of teachers $(90.32 \%)$ is sure that a WebQuest can be done both in classroom and out of it.

The results of our research show that preference was given to the summative assessment (by $41.94 \%$ of teachers). About a quarter $(25.80 \%)$ of teachers chose formative assessment. More than one third of the teachers $(32.26 \%)$ used both kinds of assessment, which in our opinion, seems quite sound.

The duration of the WebQuest learning in each case is determined by the specifics of a particular ESP course. We defined the following types of WebQuests: short-term (one-two weeks), medium-term (one-two months), and long-term (one semester). More than half of the ESP teachers $(58.06 \%)$ preferred medium-term WebQuests, about a quarter of them $(25.80 \%)$ mostly used short-term WebQuests, some teachers $(6.45 \%)$ choose rather long-term WebQuests. Also, 9.68\% of ESP teachers could use WebQuest of different duration. We can say that the choice of such types of WebQuests correlated with the aims of the educational process.

The teachers' views on the most appropriate number of performers of WebQuests are diverse. The most acceptable (chosen by $45.16 \%$ of teachers) format of organization of WebQuests was a small group, because any problem can be solved better if the learners can express their thoughts, share their opinions and find common solutions. Almost all ESP teachers $(93.55 \%)$ tend to focus more on WebQuests to develop integrated rather than discrete skills. 


\section{DISCUSSION}

\subsection{Classification of WebQuests used for IT students}

Dodge (1997; 1999) suggested a taxonomy of tasks (retelling, compilation, creative, scientific, persuasion, analytical, consensus, self-knowledge, journalistic, designing, judgment, mystery tasks) and distinguished short-term and long-term WebQuests. Taking into account the results of his study, as also the experience of teaching ESP to IT students at technical universities, we have classified WebQuests according to the following criteria: duration of WebQuest, number of performers, type of WebQuest tasks, types of language learning skills to be developed, a possibility to differentiate tasks, a place where a WebQuest is performed, type of the final product, level of learners' autonomy, type of assessment, type of learning content (Table 1).

Table 1 WebQuest classification

\begin{tabular}{|c|c|}
\hline Criteria for WebQuest & Types of WebQuests \\
\hline 1. Duration of WebQuest & 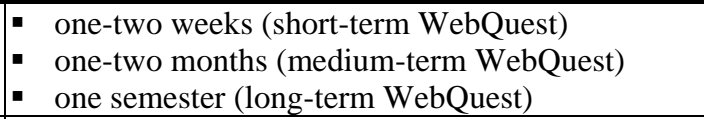 \\
\hline 2. Number of performers & $\begin{array}{l}\text { - } \text { one individual } \\
\text { - } \text { a pair } \\
\text { - } \text { a whole academic group }\end{array}$ \\
\hline 3. Type of WebQuest tasks & $\begin{array}{l}\text { separate tasks (retelling tasks, compilation tasks, } \\
\text { creative product tasks, scientific tasks, } \\
\text { persuasion tasks, analytical tasks, consensus } \\
\text { building tasks, self-knowledge tasks, journalistic } \\
\text { tasks, designing tasks, judgment tasks) } \\
\text { combined tasks }\end{array}$ \\
\hline $\begin{array}{l}\text { 4. Types of language learning skills to } \\
\text { be developed }\end{array}$ & $\begin{array}{l}\text { - } \quad \text { discrete skills (listening, speaking, reading, writing) } \\
\text { - integrated skills (for example, writing and reading) }\end{array}$ \\
\hline 5. Possibility to differentiate the tasks & $\begin{array}{l}\text { differentiated (according to learning styles and / } \\
\text { or English proficiency levels) tasks } \\
\text { non-differentiated tasks }\end{array}$ \\
\hline $\begin{array}{l}\text { 6. Place where a WebQuest is } \\
\text { performed }\end{array}$ & $\begin{array}{l}\text { - in classroom } \\
\text { - } \text { out of classroom } \\
\text { - both }\end{array}$ \\
\hline 7. Type of a final product & $\begin{array}{ll}\text { - } & \text { oral } \\
\text { - } & \text { written } \\
& \text { combined } \\
\end{array}$ \\
\hline 8. Level of learners' autonomy & 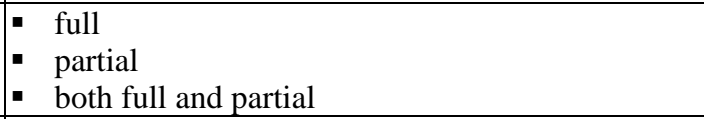 \\
\hline 9. Type of assessment & $\begin{array}{l}\text { - } \text { formative } \\
\text { - } \text { summative } \\
\text { both formative and summative }\end{array}$ \\
\hline 10. Content type & - professionally oriented \\
\hline
\end{tabular}




\subsection{WebQuest structure used in the differentiated ESP instruction}

The structure of the WebQuest is important since it provides an algorithm which helps the teacher to guide the students through their research activity. According to Dodge (1997), the WebQuest includes the following stages: introduction, task, process, resources, evaluation, conclusion. We considered them in the context of the differentiated ESP instruction.

The introduction stage aims at outlining the context of the WebQuest topic, showing its relevance for IT students.

The task stage focuses on a communicative situation which is to be realized.

The process stage determines the steps the students should take in order to solve a problem. At this stage, IT students can be differentiated according to their dominant language learning style (Synekop, 2018). For example, students with the dominant visual modality use scaffolding like tables or diagrams. The students with the dominant auditory modality are suggested activities in which they interact with each other, discuss the problems. The students with the dominant kinesthetic modality can conduct a survey and use such scaffolding as cards. Also at this stage, differentiated activities can also be suggested according to the English proficiency level.

The resources stage offers a list of Internet-resources that help IT students to solve the problem. The Internet-resources can also be differentiated according to the complexity level.

The evaluation stage suggests different scales with criteria for assessment of the final product such as a discussion assessment scale, writing assessment scale, group selfassessment checklist. The final product of the students with various English proficiency levels is evaluated in different ways: the IT students who perform complicated tasks get higher grades and the IT students who perform less complicated tasks get lower grades.

The conclusion stage implies IT students' summarizing their achievements and reflecting on them, which may inspire them to continue studying the topic.

\subsection{Approaches to WebQuest learning used by ESP teachers in the differentiated instruction}

Based on the experience of participants of our study, we singled out the main approaches to WebQuest learning which were used in differentiated ESP instruction: student-centered, experiential, reflective and collaborative approaches.

Student-centered approach helped to focus on an active learner with an emphasis on his/her professional interests, needs, and experience in ESP learning. Additionally, different language learning styles and English proficiency levels of learners who followed their own trajectories at their own individual pace were taken into account. This helped to create favorable learning environment in which the learner was motivated and responsible for the learning outcomes. Using WebQuest as technique in the teaching and learning process allowed ESP teachers to differentiate tasks according to various learners' language learning styles and English proficiency levels. IT students could make a choice about what to do and how.

Experiential approach is based on "a holistic integrative perspective on learning that combines experience, perception, cognition, and behavior" (Kolb 2015, p. 31). On the one hand, the effectiveness of learning depends on learners' ability to perceive and process information, learners' motivation and self-regulation. On the other hand, learning efficacy 
relies on learners' participation in learning activities through which they gain foreign language and professional experience. Thus, learner's professional communicative knowledge and skills are constructed or shaped through upgrading their experience. It, in turn, leads to the development of communicative competence. Using WebQuest as a role play gave students an opportunity to immerse in role-playing and practise their English communication skills in the IT field, as well as extend their professional knowledge.

Reflective approach was also incorporated into the learning process with the use of the WebQuest tool. Reflection is an inseparable part of experiential approach because it "turns experience into learning" (Boud, Keogh and Walker, 1985) and development. It implies the learner's ability to realise, analyze and rethink the experience in order to compare his/her achievements with their level of knowledge and skills development at the initial stage of ESP learning. All the stages of creating a WebQuest, starting with the introduction stage, when the students should understand the problem, and ending with the conclusion stage, when they summarize their results, imply the development of reflective skills.

Collaborative approach "strongly correlates with the provisions of experiential approach and promotes the development of students' interpersonal skills and abilities to serve as a team member" (Korol 2019, p. 118). The learners in homogeneous or heterogeneous groups actively participated in solving the problem of WebQuest and creating the final product. They worked interactively while searching for information, generating ideas, discussing problems, commenting suggestions and evaluating the outcomes.

\section{LIMITATIONS}

The current study was focused on defining the specifics of using WebQuests in differentiated ESP instruction at technical university and determining the attitudes of ESP teachers to the use of this technology. The research was limited to Ukrainian participants only (31 teachers); however, similar surveys can be conducted on the data sets of different countries to receive new insights. Additionally, the quantitative research design can be used to determine the effectiveness of WebQuest technology in differentiated ESP instruction.

\section{CONCLUSION}

Our study shows that ESP teachers have positive attitudes to the use of the WebQuest learning and the flexibility of this technology permits using it in the differentiated ESP instruction. The analysis of WebQuest specifics allowed us to suggest a WebQuest classification based on ten criteria. Also, the structure of the WebQuest was focused on differentiation of IT students according to the language learning style and foreign language proficiency level. The use of student-centered, experiential, reflective and collaborative learning approaches helped the teachers to organize and guide differentiated WebQuest activities. The conclusion was made that the use of various types of WebQuests with focus on learners' differentiation not only helps to diversify the ESP learning at technical university, but also facilitates the development of professional communicative skills. 


\section{REFERENCES}

Abbit, Jason and Ophus, John. 2008. What we know about the Impacts of WebQuests: A review of research. AACE Journal 16(4):441-456. Retrieved February 27, 2020 from https://www.researchgate.net/publication/255639554_What_We_Know_About_the_I mpacts_of_WebQuests_A_Review_of_Research

AL-Khataybeh, Majid Mohammad and AL-Awasa, Asmaa Salem. 2016. "The Effect of Using WebQuests on Improving Seventh Grade Female Students' Writing Skills in Southern AL-Mazar Directorate of Education." Journal of Education \& Social Policy 3(1):112-127. Retrieved February 27, 2020 from http://jespnet.com/journals/Vol_3_ No_1_March_2016/13.pdf

Berezova, Liudmyla V., Mudra, Svitlana V. and Yakushko, Kateryna H. 2018. "The Effect of WebQuests on the Writing and Reading Performance of University Students." Information Technologies and Learning Tools 64(2):110-118. https://doi.org/10. 33407/itlt.v64i2.1979

Boud, David, Keogh, Rosemary, and Walker, David. 2005. Reflection: Turning Experience into Learning. London: Routledge.

Brooks-Young, Susan. 2006. Critical technology issues for school leaders. Thousand Oaks, Calif.: Corwin Press.

Diachkova, Iana. 2015. "Future Lawyers' Professionally Oriented English-Language Speaking Competence Development.” PhD diss., Kyiv National Linguistic University.

Dodge, Bernie. 1995. "WebQuests: A technique for internet-based learning." Distance Educator 1(2):10-13.

Dodge, Bernie. 1997. "Some Thoughts About WebQuests". Retrieved February 15, 2020 from http://mennta.hi.is/vefir/danska/webquest1/Some\%20Thoughts\%20About\% 20WebQuests.htm

Dodge, Bernie. 1999. "WebQuest Taskonomy: A Taxonomy of Tasks.” Retrieved February 15, 2020 from http://webquest.org/sdsu/taskonomy.html

Halat, Erdogan. 2008. "A Good Teaching Technique: WebQuests". The Clearing House: A Journal of Educational Strategies, Issues and Ideas 81:3, 109-112. https://10.3200/tchs. 81.3.109-112

Kelly, Rebecca. 2000. "Working with WebQuests. Making the Web Accessible to Students with Disabilities." Teaching Exceptional Children 32(6): 4-13. https://10.1177/ 004005990003200601

Kolb, David A. 2015. Experiential Learning. Experience as the Source of Learning and Development. $2^{\text {nd }}$ ed. Upper Saddle River (New Jersey): Pearson Education Ltd.

Korol, Tetiana. 2019. "Translation Project as an Assessment Tool: Ukrainian Context." The Journal of Teaching English for Specific and Academic Purposes 7(1):115-123. https://doi.org/10.22190/JTESAP1901115K

MacGregor, S. Kim and Lou, Yiping. 2004. "Web-Based Learning: How Task Scaffolding and Web Site Design Support Knowledge Acquisition." Journal of Research on Technology in Education 37(2):161-175. Retrieved February 27, 2020 from https://files.eric.ed.gov/fulltext/EJ690967.pdf

Pérez, Regina Gutiérrez. 2016. Teaching the use of WebQuests to master students in Pablo de Olavide University. In New perspectives on teaching and working with languages in the digital era, edited by A. Pareja-Lora, C. Calle-Martínez, \& P. Rodríguez-Arancón 
(Eds), 95-104. Dublin: Research-publishing.net. http://dx.doi.org/10.14705/rpnet. 2016.tislid2014.425

Renau, Maria Luisa and Pesudo, Marta. 2016. "Analysis of the implementation of a WebQuest for learning English in a secondary school in Spain." International Journal of Education and Development using Information and Communication Technology 12(2):26-49. Retrieved February 27, 2020 from https://pdfs.semanticscholar.org/ 7de4/bc1166f2fe7de9955ae85076a47e693dc6ee.pdf?_ga=2.214219476.273896459.1 581763714-1482382344.1574446375

Synekop, Oksana. 2018. "Cognitive Aspect of Learning Style in Differentiated ESP Instruction for the Future IT Specialists." Advanced Education 10:40-47. https://doi.org/ $10.20535 / 2410-8286.151271$

Tuan, Luu Trong. 2011. "Teaching Reading through WebQuest." Journal of Language Teaching and Research 2(3):664-673. Retrieved February 27, 2020 from http://www.academypublication.com/issues/past/jltr/vol02/03/21.pdf 